\title{
Toward a Standard Benefit-Cost Methodology for Publicly Funded Science and Technology Programs
}

\section{Jeanne Powell}

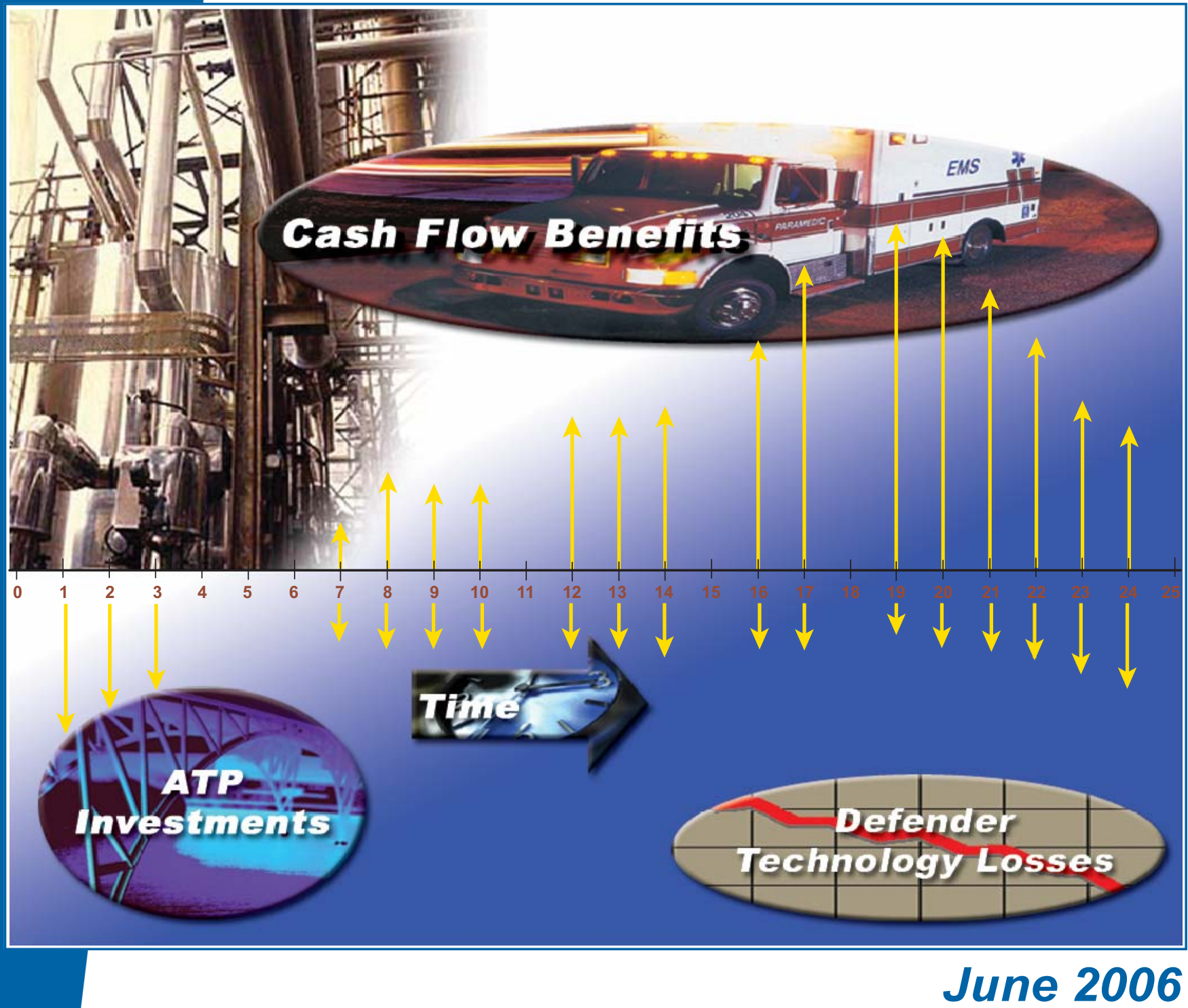

NLT 


\section{About ATP's Economic Assessment Office}

The Advanced Technology Program (ATP) is a partnership between government and private industry to conduct high-risk research to develop enabling technologies that promise significant commercial payoffs and widespread benefits for the economy.

Since the inception of ATP in 1990, ATP's Economic Assessment Office (EAO) has performed rigorous and multifaceted evaluations to assess the impact of the program and estimate the returns to the taxpayer. To evaluate whether the program is meeting its stated objectives, EAO employs statistical analyses and other methodological approaches to measure program effectiveness in terms of:

- Inputs (program funding and staffing necessary to carry out the ATP mission)

- Outputs (research outputs from ATP supported projects)

- Outcomes (innovation in products, processes, and services from ATP supported projects)

- Impacts (long term impacts on U.S. industry, society, and economy)

\section{Key features of ATP's evaluation program include:}

- Business Reporting System, a unique online survey of ATP project participants, that gathers regular data on indicators of business progress and future economic impact of ATP projects.

- Special Surveys, including the Survey of Applicants and the Survey of Joint Ventures.

- Status Reports, mini case studies that assess ATP projects on several years after project completion, and rate projects on a scale of zero to four stars to represent a range of project outcomes.

- Benefit-cost analysis studies, which identify and quantify the private, public, and social returns and benefits from ATP projects

- Economic and policy studies that assess the role and impact of the program in the U.S. innovation system

EAO measures against ATP's mission. The findings from ATP surveys and reports demonstrate that ATP is meeting its mission:

- Nine out of 10 organizations indicate that ATP funding accelerated their R\&D cycle.

- The existence of a "Halo Effect." As revealed by EAO surveys, shows that an ATP award establishes or enhances the expected value in the eyes of potential investors.

- ATP stresses the importance of partnerships and collaborations in its projects. About 85 percent of project participants had collaborated with others in research on their ATP projects.

Contact ATP's Economic Assessment Office for more information:

- On the Internet: www.atp.nist.gov/eao/eao_main.htm

- By e-mail: atp-eao@nist.gov

- By phone: 301-975-8978, Stephanie Shipp, Director, Economic Assessment Office, Advanced Technology Program

- By writing: Economic Assessment Office, Advanced Technology Program, National Institute of Standards and Technology, 100 Bureau Drive, Stop 4710, Gaithersburg, MD 20899-4710 


\section{Toward a Standard Benefit-Cost Methodology for Publicly Funded Science and Technology Programs}

Jeanne Powell

Economic Assessment Office Advanced Technology Program

June 2006

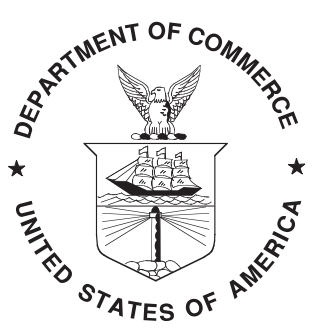

U.S. DEPARTMENT OF COMMERCE Carlos. M. Gutierrez, Secretary

TECHNOLOGY ADMINISTRATION Robert Cresanti, Under Secretary of Commerce for Technology

NATIONAL INSTITUTE OF STANDARDS AND TECHNOLOGY William Jeffrey, Director

ADVANCED TECHNOLOGY PROGRAM Marc G. Stanley, Director 


\section{Abstract}

The Economic Assessment Office of the Advanced Technology Program (ATP) seeks to develop a standard methodology for undertaking benefitcost studies of science and technology projects for purposes of quantifying federal program impacts. A key objective is to facilitate comparability and aggregation among benefit-cost studies of individual projects. This report discusses similarities and differences among the ATP's benefit-cost studies performed to date. The emphasis is on identifying methodological steps that can be taken to facilitate consistency and comparability across studies and aggregation of results of studies performed at different times. Such aggregation is needed to enable analysis across a portfolio of projects funded by a given program over time. This report draws on ATP's experience in funding risky, industry-led advanced technology projects and in conducting and publishing benefit-cost studies of nearly 30 projects. It helps extend the role of the National Institute of Standards and Technology in international, economics-based standards development by helping create a comprehensive standard benefit-cost methodology for the science and technology community.

Keywords: Advanced Technology Program; benefit-cost analysis; discounted cash flows; program evaluation; science \& technology programs; research \& development; research impacts; prospective analysis; retrospective analysis; social return on investment; public return on investment. 


\section{Acknowledgments}

The author would like to thank ATP's many contractors for their inspiration and cooperation in developing economic studies of the program's impact. Their dedication to rigorous fact finding and fruitful benefit-cost analysis, despite the uncertainties and long time horizons faced in applying this tool to early-stage R\&D projects, leaves a strong and continuing legacy. The author would like to acknowledge Lorel Wisniewski for asking for a comparison of ATP-funded studies that inspired this study and would also like to thank Stephanie Shipp and Connie Chang for their encouragement in pursuing it. Thanks are also due to Brian Belanger, Stephanie Shipp, and Lorel Wisniewski for their helpful review comments and to Harold Marshall, Building and Fire Research Laboratory, for his NIST ERB review. 


\section{Executive Summary}

The Advanced Technology Program (ATP), part of the National Institute of Standards and Technology (NIST), provides funding on a cost-shared basis for industry-led technology development projects that would most likely not be undertaken by the private sector alone. ATP uses benefit-cost studies as a major evaluation tool for quantifying long-term outcomes and impacts of its more successful projects. These studies generate metrics that directly quantify how well ATP is doing against its mission of accelerating the development of risky technologies that have broad-based economic benefit to the nation.

ATP has conducted and published benefit-cost studies of nearly 30 projects to date. ATP aggregates the measures of net national benefit reported by these studies to present a minimum estimate of portfolio earnings relative to the total costs of the program to date.

Individually, the benefit-cost studies performed to date are consistent with economic models for measuring social and private returns on public and private investment in research and development $(\mathrm{R} \& \mathrm{D})$. ATP worked directly with the leaders in the field of innovation impact measurement and growth economics to adapt public finance and business models to ATPfunded, industry-led projects. Contractors with expertise in modeling societal economic benefits applied these models in in-depth case studies of ATP projects; the case studies are based on substantial interviews of funded companies, their customers, and industry experts and on other primary data collection activities. All studies are consistent with Office of Management and Budget (OMB) Circular-A94 recommendations for the use of benefit-cost analysis in general; the underlying premise of cash-flow analysis; the use of net present value (NPV) as a key metric of program outcomes; and the Circular's specific requirements concerning features of the analysis such as discount rate, handling of inflation, and sensitivity 
analysis. ATP staff had considerable expertise in applying benefit-cost analysis in their own research before working at ATP and sought out contractors with similar expertise to perform studies for ATP. NIST economists are leaders in the international standards-setting community. Several ATP economics staff were participants in these NIST activities prior to joining ATP.

Except for studies that cover multiple technology development projects, benefit-cost studies applied to federally funded technology development projects tend to provide a "one-shot-deal" analysis. They are funded at different times in the history of the projects studied and in different years. Not all compute the same sets of metrics. As a result, impact metrics computed in different studies, particularly net present value metrics, are not strictly comparable, and aggregation across studies done at different times presents methodological challenges.

This report seeks to bridge that gap. It culminates a series of efforts to make both existing and future benefit-cost studies of ATP projects more useful to the evaluation process. Previous efforts have included an analysis of studies conducted to date, a workshop of public and private researchers, and a presentation to the American Evaluation Association.

Analysis of the published studies of approximately 30 projects revealed a great many similarities:

- All address ATP's mission. They aim to show, and succeed in showing, that ATP enables technology development that benefits industry and end users and generates broad-based benefits to the U.S. economy.

- The studies follow the economic paradigms that emphasize the market failures in early-stage technology development, the substantial gap between social returns on technology investment (public plus private) and private returns alone, and the need to determine instances in which market failures will prevent this gap from being filled without government assistance.

- Substantial "bottom-up" interviews are conducted with ATP-funded company representatives and customers, as well as other market research, to estimate the benefits of ATP-funded technologies (compared with existing defender technology as a minimum counterfactual to ATP funding) and market demand. In general, benefits are estimated on the basis of a single product unit sold and are extended to an estimated market. Studies assess the effect of ATP funding on the scope and timing of the projects.

- Cash-flow analysis techniques are implemented consistent with public finance literature and good practice in both public and private investment analysis. 
- The studies compute the same basic metrics: net present value, benefitto-cost ratio, and internal rate of return.

- Considerable uncertainties exist about the impacts being measured.

Further comparison with the guidelines for benefit-cost analysis provided by OMB Circular A-94 revealed that the published studies were consistent with those requirements.

- The studies emphasize the net present value of outcomes.

- They consistently use the OMB-mandated rate of $7 \%$ (real rate) in discounting benefits and costs to a common base year.

- They consistently estimate benefits and costs in constant dollars, generally using the dollar value at the time the study was conducted.

- They address uncertainties and include some sensitivity analysis.

OMB Circular A-94, however, does not provide a complete framework for using these studies for evaluating R\&D project outcomes and impacts for purposes of retrospective program evaluation of actual program outcomes. It appears to be targeted more to prospective analysis of new federal programs or projects.

The analysis identified four sources of inconsistency in past ATP studies that impede the use of study results, particularly in aggregation.

- Timing of studies relative to ATP funding and the technology life cycle and the treatment of uncertainties about projected future outcomes.

- Identification of the specific counterfactual to ATP funding and the related issue of attribution to ATP in cases of multiple funding sources.

- Which metrics to use: Social returns (that is, public and private benefits on combined public-private investments) and/or public return on ATP investment?

- Different base years and different constant dollar years: Often base year and constant dollar year differ in a given study and across studies.

These areas of inconsistency were discussed with workshop practitioners and explored further for the American Evaluation Association's Annual Conference (Toronto, October 2005) and for this report in the context of three broad criteria:

- ATP's evaluation objective of measuring program impacts against the program's mission while also considering tools appropriate to the evaluation of public-private science and technology programs more broadly. 
- Quality relative to analytical models established in the economic and public finance literature and accuracy as provided by established cashflow analysis procedures used by the business community.

- Effects on consistency and comparability across studies and the ability to aggregate results of different studies.

This analysis yields the following conclusions and recommendations:

- Study timing. Highly prospective studies of project outcomes, particularly if performed before technical risks and uncertainties have been overcome and business risks significantly mitigated, may not generate credible or useful estimates of program impacts even if they meet high standards of economic modeling and rigor. Probability distributions of long-term advanced technology project outcomes are extremely difficult to estimate. Given the uncertainties about these outcomes, at a minimum some combination of retrospective and prospective (ex ante) analysis is appropriate as long as the analysis includes direct evidence of actual commercialized products or processes that incorporate the program-funded technology.

- Counterfactual and attribution. ATP-funded studies have used various mechanisms to model incremental benefits of an ATP-funded technology relative to the counterfactual situation. Mechanisms include acceleration of benefits and increased likelihood of achieving benefits. Sometimes achieving any quantifiable economic benefits from a project required funding from multiple external sources, each of which was indispensable. A conservative approach is to allocate benefits in some equitable way among funding sources. Identification and program attribution of benefits require the following: (1) matching program-funded projects to direct project outcomes to the extent practical, by tracing product outcomes backward from existing company products to their R\&D project origins and forward from the ATP-funded projects through the product development stages to identify the major intersections; and (2) considering appropriate attribution of all or partial benefits to ATP.

- Which metrics: Social return on investment and/or public return on public (ATP) investment? ATP has focused on these two sets of measures. Unfortunately, some studies produced the social return metric, which compares combined public and private benefits of ATP-funded technology with combined public and private investments; others produced just the public return on ATP's investment. (Variants of these two sets of measures of return appear in the evaluation literature, but ATP has focused on these two basic themes.) Both sets of measures have utility, and both have advantages and disadvantages. Combined publicprivate benefit-cost analysis is logical for cost-shared technology 
development projects and helps identify substantial gaps between full societal benefits and private benefits that justify federal funding; however, data collection is difficult. The public return on ATP's investment provides a clearer measure of programmatic impact against its mission of generating broad-based benefit to the nation. The best strategy would appear to be to compute both sets of measures, with attention to keeping the project definitions and traceable benefits consistent for both and to developing practical estimation techniques for computing social return metrics that alleviate data problems.

- Adjusting net present values for timing differences among studies and projects. Studies performed at different times use different base years and constant dollar years, although ATP's cluster and focused program studies all use a common constant dollar year for a given study and always use the year of first cash flows as the base year of analysis for all projects in the study. Nevertheless, other base year choices might be equally or more meaningful for such studies, for example, the year the portfolio analysis is performed.

In cases in which multiple projects are analyzed in a single study, or in which results of multiple studies are considered together to compute a minimum estimate of portfolio performance, adjustment to constant dollars across the studies will be necessary. For comparability with other studies consideration should also be given to using a common base year for discounting before aggregating across studies. This consideration should include proper interpretation of the discounting effects on metrics that result from different base year choices and an assessment of which approach makes sense for the evaluation objective.

The adjustments are a straightforward process and can be made after studies have been completed using different constant dollar years and different base years for discounting.

ATP's efforts to document and investigate methodological similarities and differences across its benefit-cost studies have demonstrated the utility and commonality of the studies, as well as the complexities beyond pure estimation issues. The challenges do not appear insurmountable. Analysis of key methodological differences among ATP's benefit-cost case studies of nearly 30 projects has helped the program assess the significance of these differences and pose solutions. The goal is to circulate this report to users of benefit-cost results and to benefit-cost analysis practitioners. Feedback is sought and anticipated with the hope that a living, working document will support a more formal, uniform standard-setting process for benefit-cost analysis in the future. 


\section{Contents}

About the Economic Assessment Office ........... Inside Front Cover

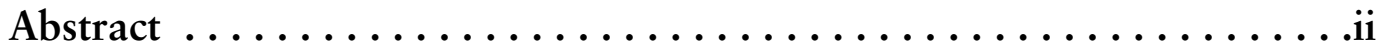

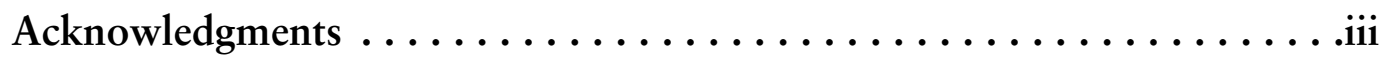

Executive Summary $\ldots \ldots \ldots \ldots \ldots \ldots \ldots \ldots \ldots \ldots \ldots \ldots \ldots \ldots \ldots$

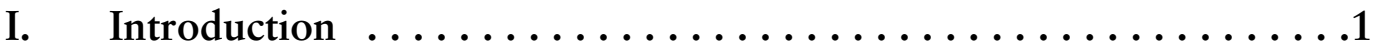

II. Rationale and History $\ldots \ldots \ldots \ldots \ldots \ldots \ldots \ldots \ldots \ldots$

III. Similarities and Differences in ATP's Studies .............13

IV. Study Timing and Uncertainties about Future Outcomes . . . . . .17

V. Identifying the Counterfactual and Attribution of Benefits ......21

VI. Which Metrics: Social Return on Investment and/or Public Return on Public (ATP) Investment? . . . . . . . . . . . . . . . .27

VII. Adjusting for Timing Differences across Studies and Projects: Constant Dollars and Base Year for Discounting ...........33

VIII. Conclusions and Future Work ..................43

References .............................45

About the Author.$\ldots \ldots \ldots \ldots \ldots \ldots$. Inside Back Cover

About the Advanced Technology Program ......... Inside Back Cover

List of Tables

1. ATP's Benefit-Cost Studies to Date $\ldots \ldots \ldots \ldots \ldots \ldots \ldots \ldots \ldots$

2. Framework of Analysis .........................

3. Study Timing and Uncertainties about Future Outcomes:

Contrasting Examples .........................18

4. Identifying the Counterfactual and Attribution of BenefitsContrasting Studies ..............................23 
5. Which Metrics? Contrasting Projects in Component-Based Software ...........................28

6. Which Metrics? Other Contrasting Studies .................29

7. Adjusting for Timing Differences across Studies and Projects: Constant $\$$ and Base Year (Example 1: Ranking Does Not Change) ..............................

8. Adjusting for Timing Differences across Studies and Projects: Constant $\$$ and Base Year (Example 2: Ranking Changes) .......36

\section{List of Figures}

1. Adjusting to Constant 2005 Dollars .....................37

2. Adjusting Base Year to $2005 \ldots \ldots \ldots \ldots \ldots \ldots \ldots \ldots \ldots \ldots \ldots \ldots$ 


\section{Introduction}

\section{Origins}

Program evaluation informs program and policy decision making concerning how well a program is working in meeting its goals and objectives. For government programs, these goals and objectives include social and economic outcomes as well as the operations of the program or its immediate outputs. Under procedures to ensure independence, program evaluation may be conducted by independent experts external to the program or by internal program managers. The subset of program evaluation comprising impact evaluation, as compared with ongoing project monitoring and reporting, assesses the net effect of a program by examining outcomes and comparing them with what would have happened in the absence of the program. Benefit-cost analysis directly compares a program's outputs and outcomes with the costs (resources expended) to produce them (Office of Management and Budget [OMB] 2004).

OMB Circular A-94 recommends benefit-cost analysis as the technique to use in a formal economic analysis of government programs or projects (OMB 1992). It states that "social net benefits, and not the benefits and costs to the Federal Government, should be the basis for evaluating government programs or policies that have effects on private citizens or other levels of government." These measurements offer the intuitive simplicity of tools employed routinely in business management and finance. However, the OMB mandate is for public programs to apply a more complex public finance model that extends the analysis to the benefits to society broadly, not just direct recipients of public funds and not to the funding agency itself. Economists have long recognized that there is often a significant divergence between private returns (i.e., the returns to the innovator) and society-wide benefits. The extended public finance models enable systematic quantification of societal returns and the divergence. 


\section{Purpose}

The Economic Assessment Office (EAO) of the Advanced Technology Program (ATP) seeks to develop a standard methodology for undertaking evaluation benefit-cost studies of science and technology (S\&T) projects it has funded for purposes of quantifying the program's outcomes and impacts. ATP seeks to go beyond treating each evaluation case study as a "one-shot deal" and to develop approaches that facilitate comparison and aggregation across different studies. ATP has conducted numerous benefitcost studies in the past that are consistent individually with OMB Circular A-94 and standard published methodologies. Some studies have analyzed a number of related projects. Although adequate to identify whether individual projects or small groups of projects analyzed together are costeffective, the net present value (net benefit) impact metrics computed in different studies are not strictly comparable, and aggregation across studies is problematic.

Differences in basic assumptions, timing, and specific metrics used do not adversely affect the value of any individual study, but they hinder the maximum use of the studies by ATP in examining its overall portfolio. In this report, ATP draws on a large body of past benefit-cost studies, the experience and knowledge gained from a workshop with a number of practitioners in June 2004, many hours of discussion with ATP's contractors, in-house analysis, and a presentation to the American Evaluation Association in October 2005 to (1) document consistencies and inconsistencies and sources of incomparability across studies and (2) frame an approach for extending the use of benefit-cost analysis from its typical use in case studies of individual "successful" projects to the evaluation of a portfolio of federal S\&T projects.

\section{ATP Background}

ATP is a government-industry partnership whose mission is to accelerate commercial development of risky, innovative technologies with potential for broad economic benefit to the nation. Its mechanism is to cost share with private industry the funding of high-risk research and development (R\&D) with broad commercial and societal benefits. Through a competitive selection process, ATP chooses projects by applying evaluation criteria:

- Scientific and technological merit $(50 \%)$

- Potential for broad-based economic benefits $(50 \%)$ 
Selection emphasizes projects that would otherwise not be undertaken because the risks are too high or because the benefits would not accrue to private investors.

Since its inception in 1990, ATP has announced 768 awards to single companies and joint ventures and has awarded approximately $\$ 2.3$ billion; industry has provided approximately $\$ 2.1$ billion as its cost share.

The program anticipates that the major benefits accrue through the creation of new products and processes embodying ATP-funded technologies and their successful commercialization. ATP's EAO seeks to measure outputs, outcomes, and impacts of these technology development projects through a comprehensive portfolio of survey and statistical techniques, case studies, and special issue studies. Generally, case studies, which include high-level overview studies of all completed projects and indepth benefit-cost studies of selected high-impact projects, are performed by independent contractors.

\section{Methodology}

ATP's methodology for this report involves the following:

1. Pursue the program evaluation objective: the evaluation of ATP program impacts against ATP's mission of accelerating the commercial development of risky technologies with the potential for broad economic benefit to the nation.

2. Examine the economics literature for the theoretical rationale and measurement history of social and private rates of return on R\&D investment.

3. Consider the OMB mandate for benefit-cost analysis, including specific requirements and general implications for evaluation of public-private S\&T projects.

4. Draw on experience and knowledge gained from an ATP workshop that convened private sector and National Institute of Standards and Technology (NIST) practitioners in June 2004.

5. Develop a general methodology from knowledge and experience derived from these external sources.

6. Analyze ATP studies conducted to date for similarities and differences and consistency with this model.

7. Identify key sources of the differences, examine their effects, and consider approaches to addressing inconsistencies. 
8. Introduce the initial version of the methodology at a presentation to the R\&D Technical Interest Group at the American Evaluation Association in October 2005.

9. Recommend next steps.

In large measure, this report is the text supporting the presentation the author made to the American Evaluation Association at its "Crossing Borders, Crossing Boundaries" Conference on October 26-29, 2005. 


\section{II.}

\section{Rationale and History}

\section{Economic Literature}

Benefit-cost methodologies applied to S\&T projects derive from Edwin Mansfield's work in the 1970s (Mansfield et al. 1977), which is aptly captured in the recent Journal of Technology Transfer issue commemorating Dr. Mansfield (Scherer 2005). Mansfield adapted his private sector analysis specifically to ATP-funded projects in a report for ATP (Mansfield 1996). His public finance approach is an extension of traditional business cash-flow analysis that applies basic concepts in public finance to measure benefits to industry users of technology products and end users as well as the innovators.

Return on investment in developing new technology is thus expanded. It includes consumer surplus in the form of cost reductions and other societal benefits experienced by technology users as well as innovators' profits from technology products and cost-reducing new processes measured relative to a hypothetical, counterfactual situation in which the new technology does not exist.

Mansfield's work provides a foundation for public sector-funded S\&T case studies following two themes:

1. His evidence that social rates of return on industry-led projects (combined public and private returns) exceed private rates of return indicates the potential for market failure in the form of underinvestment in $\mathrm{R} \& \mathrm{D}$ relative to the societal optimal level and thus possible justification for federal subsidies to $R \& D$. His pioneering work in the 1970s and subsequently in two studies sponsored by the National Science Foundation (NSF) showed private rates of return averaging $25 \%-36 \%$ and social rates of return averaging $50 \%-70 \%$. (The lower rates were reported in the 1977 study.) Several other 
studies, for example, by Scherer and Piekarz, confirmed and extended these ideas and results and discussed some of the policy issues (Teece 2005). The macroeconomic studies examining returns to R\&D, for example, by Griliches and Nadiri using broad statistical databases, showed similar results, although differences across industries were substantial (Bernstein and Nadiri 1988; Nadiri 1993).

Further comparison of private rates of return to such projects with industry and company hurdle rates provides a better indication of whether the private sector is likely to undertake such investments in the absence of federal funding. If company hurdle rates (defined here as the rate of return required to undertake an investment with a given level of risk) are high relative to opportunity cost private rates of return on projects of comparable risk, companies either will not make the investments at all or they will invest only at a minimal exploratory level, and benefits become increasingly longer term and more problematic without federal funding. If hurdle rates are comparable with private rates of return, companies are more likely to undertake a significant investment without federal funding, and federal funding may be displacing private funding (Jaffe 1996, 1998).

Quantification of the difference between social and private rates of return, called the "spillover gap," and evidence that private rates are below industry or company hurdle rates become program measurement objectives. The theoretical basis of analysis is that a spillover gap justifies public funding and, therefore, quantification of it is a primary program evaluation objective. $R \& D$ will be underinvested, and projects merit consideration for public funding to the extent that private rates are below social rates of return and therefore $\mathrm{R} \& \mathrm{D}$ is unlikely to be funded at a socially optimal level. The case is even clearer if private rates of return are below the investment hurdle rate for risky $\mathrm{R} \& \mathrm{D}$ and, therefore, the investment most likely would not be made at all without federal funding (Jaffe 1996, 1998).

2. Mansfield establishes a case study method supported by customized data collection as an appropriate methodological tool of economic analysis. Scherer quotes Mansfield's statement: "If you want to know something, ask the people who know" (Scherer 2005, p. 5). Mansfield described the need to interview personally not just the "doers," but also the beneficiaries among customers and users (ATP 1996). Data often do not exist for large statistical analysis of impacts but can be created at a smaller level. Teece described his instructions to his students "to collect data in the field" (Teece 2005, p. 18) and quotes Mansfield's introduction to his two volumes of collected papers: "in general, my approach has been to try to get a reasonably solid empirical footing before attempting to model complex phenomena about which very little is known; to keep the theoretical apparatus as 
simple, transparent and robust as possible; to collect data directly from firms (and other economic units) carefully tailored to shed light on the problem at hand (rather than to try to adapt readily available generalpurpose data, which is often hazardous), and to check the results as thoroughly as possible with technologists, executives, government officials and others who are close to whatever phenomenon is being studied" (Mansfield 1995, p. ix). The advantage is that questions and resulting data are targeted to what you really need to know.

\section{OMB Circular A-94}

OMB's mandate that federal programs use benefit-cost analysis or costeffectiveness analysis goes back several decades before Circular A-94 was revised in 1992. Most of the Circular A-94 presentation is geared to a prospective analysis of an entire federal program and provides little guidance for evaluating project and program outcomes and impacts, in general, or basic and applied S\&T programs, in particular. It predates government-wide mandates for program performance metrics and is more comprehensive and technically challenging than could easily be imposed or implemented by all agencies. Nevertheless, Circular A-94 is a methodology tool for program evaluation efforts stimulated by the Government Performance and Results Act (GPRA) (1993). Its guidelines are consistent with good practice for both retrospective and prospective analyses, at the program or project level, and for any program area.

OMB Circular A-94 establishes the following guidelines:

\section{Outcome Measures}

1. Use net present value as the standard criterion for deciding whether a government program can be justified on economic principles.

2. When an analysis of competing alternatives is done, consider in addition the present value of benefits relative to a given amount of cost, or vice versa, the cost relative to a given amount of benefits, all measured in present value terms.

3. Be explicit about underlying assumptions.

\section{Net Benefits Measurement}

1. Use the net benefits to society, not to the federal program, as the basis for evaluating government programs.

2. Identify incremental benefits and costs relative to the situation in which the government program does not operate. Record displaced activities as a cost.

3. Include effects on U.S. citizens, and not on others.

4. Use consumer surplus and "willingness to pay" as measures of value beyond what is captured in market prices. 
5. Assume full employment of resources. Avoid multiplier-based estimates of effects of government spending on the economy.

\section{Treatment of Inflation}

1. Use real or constant dollar values to perform analyses.

2. Use the administration's GDP deflator if an inflation adjustment is needed.

\section{Use of Discount Rate}

1. Report net present value and other outcomes using a real discount rate of $7 \%$ in performing constant-dollar benefit-cost analyses of proposed public investments and regulations. This rate is intended to approximate a marginal pretax rate of return on an average investment in the private sector.

\section{Treatment of Uncertainty}

Typically, estimates of benefits and costs are uncertain.

1. Identify sources of uncertainty, provide expected value estimates, and test sensitivity of estimates to important sources of uncertainty.

2. Where possible, derive a probability distribution for benefits, costs, and net benefits.

The Circular A-94 guidance is applicable and appropriate either to prospective program-level analyses or to retrospective and prospective project-level analyses. It provides minimum requirements for benefit-cost analysis of an individual project; however, it does not address problems of aggregation of results for projects and studies performed at different times, and it does not provide guidance specific to S\&T programs. This report seeks to fill in some of those gaps.

\section{NIST and ATP}

NIST's economists have been actively engaged for nearly 40 years in cash flow-based benefit-cost analysis in microeconomic case studies of R\&D projects. NIST's Building and Fire Research Laboratory (BFRL) economists are leaders in the international standards community. Their work in building and energy economics includes development and application of life cycle cost models for energy conservation investments and development and implementation of training programs. NIST's BFRL economists' work in modeling and building economics standards has resulted in a series of American Society for Testing and Materials (ASTM) standards for building economics (ASTM 2004). And their work for NIST and other agencies has sometimes entailed program evaluation. Several members of 
the ATP economics staff were participants in these BFRL activities before joining ATP.

Benefit-cost case studies became a cornerstone of the evaluation of longterm outcomes of NIST's laboratory programs in the 1980s and in planning studies for new programs. More than 30 separate studies have been commissioned by NIST's Program Office. For more information see the NIST Web site: http://www.nist.gov/director/planning/ impact_assessment.htm.

ATP's founding legislation required the evaluation of program outcomes before that practice was common or required by GPRA. ATP naturally drew on the BFRL and NIST experience. In addition, ATP drew on Albert Link's growing involvement in program evaluation, including his benefitcost studies of outcomes of a number of NIST laboratory projects for the NIST Program Office during the 1980s. Albert Link helped ATP draft a preliminary plan for program evaluation. In its early years, ATP funded Link to undertake several early benefit-cost studies that focused on research cost savings to industry that result from avoiding redundant research through federal sponsorship and the cost sharing of technology development by industry consortia. ATP engaged Ed Mansfield and others to develop appropriate methodologies for assessing longer-term economic impacts using benefit-cost (among other) techniques. Since that time, more than a dozen benefit-cost studies have been published. Several published studies analyze groups of related ATP-funded projects.

Twelve of these studies, covering 28 ATP projects, are listed in Table 1. The cost of conducting these studies ranged from $\$ 25,000$ to $\$ 357,000$ (not adjusted for inflation). More than half of the studies focused on one ATP project; the rest covered from two to eight ATP projects. All are available on ATP's Web site: http://www.atp.nist.gov/eao/eao_pubs.htm.

\section{Other Agencies}

Although a regular tool of public finance, benefit-cost analysis for evaluating program impacts of federal S\&T programs has not been common outside NIST and ATP. As the Government Performance and Results Act (GPRA) ${ }^{1}$ percolated through agencies in the early 1990s, information sharing increased, and interagency evaluation networks and workshops evolved with ATP participation. ATP staff engaged in training

1. Enacted in 1993, the GPRA provides for the establishment of strategic planning and performance measurement in the federal government. 
Table 1. ATP's Benefit-Cost Studies to Date

\begin{tabular}{|c|c|c|c|c|}
\hline Short Title (\# of projects) & Number & Contractor & Pub Date & $\begin{array}{l}\text { Study } \\
\text { Cost-\$ }\end{array}$ \\
\hline Photonics cluster (2) & GCR 05-879 & Delta Research & 2005 & 228,000 \\
\hline Composites cluster (2) & GCR 04-863 & Delta Research & 2004 & 200,000 \\
\hline $2 \mathrm{~mm}$ project-retrospective (1) & GCR 03-856 & MIT & 2004 & 357,000 \\
\hline HDTV joint venture (1) & GCR 03-859 & RTI International & 2004 & 75,000 \\
\hline $\begin{array}{l}\text { A-Si Detectors for digital } \\
\text { mammography (1) }\end{array}$ & GCR 03-844 & Delta Research & 2003 & 136,000 \\
\hline Component-based software (8) & GCR 02-834 & RTI International & 2002 & 154,000 \\
\hline Closed-cycle refrigeration (1) & GCR 01-819 & Delta Research & 2001 & 77,000 \\
\hline Digital data storage (2) & GCR 00-790 & RFF & 2000 & 138,000 \\
\hline $\begin{array}{l}\text { Flow-control machining in } \\
\text { auto industry (1) }\end{array}$ & NISTIR 6373 & $\begin{array}{l}\text { NIST-Building } \\
\text { \& Fire Research }\end{array}$ & 1999 & 90,000 \\
\hline Tissue engineering (7) & GCR 97-737 & RTI International & 1998 & 122,000 \\
\hline 2mm—Early assessment (1) & GCR 97-709 & CONSAD & 1997 & 25,000 \\
\hline Printed wiring board (1) & GCR $97-722$ & Albert N. Link & 1997 & 22,500 \\
\hline
\end{tabular}

programs and participated in a variety of evaluation forums. The OMB Performance Assessment Rating Tool (PART) was born in 2002. ${ }^{2}$ Throughout their interactions with other agencies, ATP staff members encountered few examples of benefit-cost analysis outside NIST. In the R\&D-S\&T arena, agencies had been relying largely on anecdotal information and peer review. Data difficulties and outcome uncertainties abound for all programs.

Nevertheless, benefit-cost analysis offers considerable promise for bridging economic analysis to traditional financial analysis tools and metrics that

2. In 2002 the Director of the Office of Management and Budget (OMB) announced development of the PART for formally evaluating the effectiveness of federal programs. He described the PART's purposes as follows: "The PART is a systematic method of assessing the performance of program activities across the Federal Government. The PART is a diagnostic tool; the main objective is to improve program performance. The PART assessments help link performance to budget decisions and provide a basis for making recommendations to improve results." 
agency stakeholders understand. And it provides an approach to directly measure program impact on the economy. ATP's authorizing legislation requires economic evaluation and such metrics and thus gave ATP a head start. GPRA and PART requirements now facing all U.S.-government funded programs are somewhat broader but have the same goal: to demonstrate outcomes and impacts affecting society broadly, beyond the immediate program participants.

\section{ATP-Sponsored Workshop on Selected Methodological Issues in Benefit-Cost Analysis}

ATP's Economic Assessment Office conducted a one-day workshop in June 2004 to address a small number of issues that had become apparent in the course of sponsoring benefit-cost studies. Evaluation practitioners who had conducted studies for ATP or who had expressed interest in benefit-cost analysis were invited to the workshop at NIST. NIST experts were invited also. The workshop had 15 participants, with varying experience in these types of studies. Through structured questioning, workshop participants addressed a number of issues arising in the course of ATP's studies.

\section{Topic 1: Measures of Performance}

- Social (public plus private) returns or public returns

- Advantages and disadvantages of each approach

- Approaches to sensitivity analysis

- Comparison/aggregation across multiple project cases

\section{Topic 2: Attribution to ATP}

- What is the appropriate counterfactual? Is it different for different types of measures?

- What effect do multiple funding sources have?

- What effect does joint venture participation have?

\section{Topic 3: When is the best time to study project performance?}

- After technology hurdles have been overcome? After commercialization has begun? Later?

- What are best approaches to dealing with uncertainties about project outcomes in conducting prospective and/or partially prospective analyses?

\section{Topic 4: Bridging the gap from microeconomic case study to macroeconomic effects}

- What are the basic requirements for implementing macro models successfully?

- Is it feasible to convert existing micro case studies to the macro level? 
- Is it feasible to aggregate existing case studies to generate input to a macro model?

The discussions cited the overarching role of OMB Circular A-94 and highlighted similarities, consistency, and good practice in existing studies. The discussions also demonstrated the need to pursue approaches to thorny issues in which experienced practitioners either were in some disagreement about the best practice or had not considered the issue. Practitioners clearly were focused on providing quality studies that followed established principles and good practice; however, they disagreed somewhat on what metrics should be presented among economically appropriate choices. They focused on delivering a high-quality product for their own specific contracted work. They had thought little about the way federal programs should present results of different studies performed at different times in project lives by different contractors. 


\section{III.}

\section{Similarities and Differences in ATP's Studies}

ATP has used aggregates of results of benefit-cost studies in comparing benefits from the limited number of projects for which such studies have been done with the entire costs of the Advanced Technology Program to date. These comparisons have often showed that estimated benefits exceed program costs to date by more than an order of magnitude. However, the results of this portfolio analysis were known to be very rough approximates of portfolio minimum performance, given that the studies were performed at different times and at different stages of project life cycles, a mix of retrospective and totally prospective benefits were quantified, and somewhat different metrics were reported. In addition, assumptions used in highly prospective studies sometimes proved too optimistic over time.

In recognition of these difficulties, ATP economists seek to develop a more comprehensive, integrated approach to benefit-cost studies that will support aggregation of results and comparability. With the passage of time, the possibilities for more retrospective analysis improve.

As a foundation for such an integrated effort, ATP has documented the similarities and differences across its benefit-cost studies that appear to affect the ability to combine results of individual studies to describe overall impacts of the program to date.

\section{Similarities}

ATP's benefit-cost studies have much in common:

- All address ATP's mission. They aim to show, and succeed in showing, that ATP enables technology development that benefits industry and end users and generates broad-based benefits to the U.S. economy. 
- The studies follow the analytical paradigms of Mansfield and Jaffe, which emphasize (1) the large size of public benefits relative to private benefits that can often be expected from enabling new technologies (Mansfield et al. 1977), (2) the role for federal funding in addressing market failures in early-stage technology development (Jaffe 1996), (3) the substantial gap between social returns on technology investment (public plus private) and private returns alone (Mansfield et al. 1977; Jaffe 1996), and (4) the need to determine where federal funding is needed for these benefits to occur (Jaffe 1996, 1998).

- Substantial "bottom-up" interviews with ATP-funded company representatives and customers are involved, as well as other market research, to estimate benefits of ATP-funded technologies (relative to existing or anticipated defender technology) and market demand. In general, benefits are estimated on the basis of a single product unit sold and extended to an estimated market. In instances in which the project would most likely have been funded at some level without ATP, the studies assess the effect of ATP funding on scope and timing of the projects compared with a hypothetical counterfactual situation without ATP funding.

- The studies implement cash-flow analysis techniques consistent with public finance literature and good practice in both public and private investment analysis.

- The same basic metrics are computed: net present value, benefit-to-cost ratio, and internal rate of return.

- Considerable uncertainties exist about impacts being measured.

- The studies are consistent with OMB Circular A-94 in computing the net present value of outcomes as the key metric of cost-effectiveness.

- They consistently use the OMB-mandated rate of $7 \%$ (real rate) in discounting benefits and costs to a common base year.

- They consistently estimate benefits and costs in constant dollars, generally using the dollar value at the time the study was conducted.

- They address uncertainties and include some sensitivity analysis.

- The studies follow similar approaches to estimating period of economic benefits. None assume more than 10 years; all consider competing developments and assess the economic life of the technology.

- ATP projects a priori believed to be economically successful and therefore worth the investment in the study are selected for these studies, although some studies cover a broader cluster or portfolio of projects.

- Study results are not assumed to be representative of the outcomes for the portfolio of ATP projects and are not presented as such. Instead they are presented as impacts of some of ATP's more successful projects. In aggregation, the estimated impact of these projects alone is assumed to be no better than a minimum of impact for the entire portfolio. ATP uses 
other evaluation tools, including high-level overview case studies and a composite performance rating system, to examine all projectssuccessful and unsuccessful. The quantitative benefit-cost studies examine only some of the more successful projects for which advance screening suggested substantial measurable economic and social impact.

\section{Differences}

Comparability of studies, potential for aggregating results across studies, and actual utility in program evaluation are affected by a number of factors. From hindsight, ATP economists are learning how to compensate for some nonoptimal conditions and plan to address some key sources of difference in ongoing efforts such as this methodological study and further case studies. Differences can be summarized as follows:

- Timing of studies and uncertainties about projected future outcomes

- Which metrics? Social returns (that is, public and private benefits on combined public-private investments) and/or public return on ATP investment

- Identification of specific counterfactual to ATP funding

- Attribution to ATP given multiple funding sources

- Different base years and different constant dollar years (base year and constant dollar year often differ in a given study and across studies)

\section{Framework of Analysis}

The rest of this report examines these differences as evidenced in our portfolio of published studies. We draw on results of the workshop and the more comprehensive analysis of differences across our portfolio to start laying a foundation for a standard approach to benefit-cost analysis for publicly funded R\&D projects. Three criteria are applied in considering an appropriate standard approach:

- ATP's evaluation objective of measuring program impacts against the program's mission while also more broadly considering tools appropriate to the evaluation of public-private science and technology programs

- Quality relative to analytical models established in the economic and public finance literature and accuracy as provided by established cashflow analysis procedures used by the business community

- Effects on consistency and comparability across studies and the ability to aggregate results of different studies

The matrix shown in Table 2 illustrates this framework. 
Table 2. Framework of Analysis

\begin{tabular}{l|l|l|l}
\hline & $\begin{array}{c}\text { Evaluation } \\
\text { Objective }\end{array}$ & $\begin{array}{c}\text { Quality } \\
\text { and Accuracy }\end{array}$ & $\begin{array}{c}\text { Comparability } \\
\text { and Consistency }\end{array}$ \\
\hline $\begin{array}{l}\text { Timing of study and } \\
\text { uncertainties about } \\
\text { benefit outcomes }\end{array}$ & & & \\
\hline $\begin{array}{l}\text { Which metrics: } \\
\text { Social and/or public? }\end{array}$ & & & \\
\hline $\begin{array}{l}\text { Role of ATP: Identifying } \\
\text { the counterfactual and } \\
\text { appropriate attribution } \\
\text { to ATP }\end{array}$ & & & \\
\hline $\begin{array}{l}\text { Adjusting for } \\
\text { time differences: } \\
\text { Base year } \\
\text { Constant dollars }\end{array}$ & & & \\
\hline
\end{tabular}

The analysis is limited to studies that used standard cash flow-based financial analysis techniques envisioned in OMB Circular A-94, although many of the issues addressed apply similarly to other quantitative case study approaches. 


\section{IV.}

\section{Study Timing and Uncertainties about Future Outcomes}

\section{What Are the Issues?}

Technology development benefits as measured by outcomes and impacts are highly uncertain and dependent events. At the time that ATP funds a given technology development project, the risks of technical failure (or of meeting only limited technical objectives) are very high. By the end of the period of ATP funding, technical hurdles are reduced; however, even for projects deemed successful technically, generally, significant R\&D is still needed before the technology has significant economic value. Market, financial, and business risks remain high even for projects achieving a high level of technical success. Product development phases are often more costly than early-stage R\&D financing such as ATP funds. In some technology areas, the time to full commercialization after ATP funding ends can be a decade or more.

Nevertheless, ATP initiated benefit-cost studies early on in the brief 15 -year history of the program-partly because the economics staff had significant expertise in these methodologies, but also because of pressure from stakeholders for quantitative program impacts. At the time the earliest studies were conducted, no ATP projects had fully matured. ATP had no experience with the range of outcomes that should be anticipated, and the empirical data available to independent researchers for assessing technology risks and adoption were extremely limited. No one had a good sense of the true probability distributions.

The more recent studies were conducted somewhat later in the technology life cycle. Technology risks had been reduced, and projects studied had made significant progress toward commercialization. All of the studies conducted to date were either entirely or partially prospective analyses. The recent ones have had a retrospective component, and/or barriers to substantial economic impact were considered small. ATP attempts to use 
results from all of the studies to construct a minimum of the net benefits of the program.

\section{Contrasting Examples}

Table 3 illustrates this variability in timing by contrasting two large studies that examined a number of different ATP projects funded in the areas of tissue engineering and component-based software. The two studies were performed by the same independent research organization.

\section{Table 3. Study Timing and Uncertainties about Future Outcomes: Contrasting Examples}

\begin{tabular}{|c|c|c|c|}
\hline Study & $\begin{array}{l}\text { Timing Relative } \\
\text { to ATP Funding }\end{array}$ & Technology Status & Treatment of Uncertainty \\
\hline \multirow[t]{2}{*}{$\begin{array}{l}\text { Tissue engineering } \\
\text { ( } 7 \text { cases) }\end{array}$} & \multirow[t]{2}{*}{$\begin{array}{l}\text { Early in ATP for } \\
3 \text { cases; soon after } \\
\text { ATP \$ ended for } \\
4 \text { cases }\end{array}$} & \multirow[t]{2}{*}{$\begin{array}{l}\text { Technologies not } \\
\text { developed and/or not } \\
\text { ready for } \\
\text { commercialization } \\
\text { (Biotech projects have } \\
\text { very long timeline) }\end{array}$} & $\begin{array}{l}\text { Barriers to meeting technical } \\
\text { and economic goals not } \\
\text { assessed. Sensitivity analysis } \\
\text { performed, but showed results } \\
\text { not very sensitive to input } \\
\text { variables tested. }\end{array}$ \\
\hline & & & $\begin{array}{l}\text { To be conservative, only one } \\
\text { application considered per case. }\end{array}$ \\
\hline \multirow[t]{2}{*}{$\begin{array}{l}\text { Component-based } \\
\text { software } \\
\text { (8 cases) }\end{array}$} & \multirow[t]{2}{*}{$\begin{array}{l}\text { Soon after ATP } \\
\$ \text { ended }\end{array}$} & \multirow{2}{*}{$\begin{array}{l}\text { Technologies complete; } \\
\text { in commercialization } \\
\text { (IT projects have short } \\
\text { timelines) }\end{array}$} & $\begin{array}{l}\text { Selection emphasized projects } \\
\text { with revenues to date and } \\
\text { near-term prospects. }\end{array}$ \\
\hline & & & $\begin{array}{l}\text { Benefit analysis quantified only } \\
\text { products actually on the market } \\
\text { and assumed short product lives. }\end{array}$ \\
\hline
\end{tabular}

The tissue engineering study was done in the mid-1990s. Performance metrics estimated in the study showed huge impacts; however, the study was conducted very early in the project life cycle of every project covered. Of the seven projects analyzed (all of those ATP had funded in the area of tissue engineering), four had completed their ATP funding period and had significant technical accomplishment; three had just recently started. All faced major continuing technical hurdles, including additional R\&D and clinical trials regulated by the Food and Drug Administration. The study included some probabilistic assessment and sensitivity analysis; however, it did not consider the full breadth of possible outcomes or provide a realistic 
weighting for them. Estimates were based on company interviews and other investigation.

The methodological emphasis was on state-of-the-art modeling of patient benefits and an illustration of the patient-benefit model to ATP's tissue engineering portfolio at the time. The treatment of uncertainty about technical and business outcomes needed for these benefits to be realized was more rudimentary, although it drew on approaches in the economics literature.

The treatment failed to take adequate account of the very early stage, risky nature of these projects. Outright technical or business failure was not envisioned as an outcome. All the projects were anticipated to yield substantial medical benefits. ATP was expected to accelerate the technology life cycle and to improve probabilities of technical success incrementally by increasing the level of $R \& D$ funding. Company-provided assessments of progress toward demonstrating technical feasibility (adjusted by progress to date) were used as a proxy for probability of technical success. The schedule for technology adoption adapted an established diffusion model that probably was not adequate for addressing the long-term, high-cost regulatory barriers to adoption of this type of technology.

From hindsight, ATP has learned that typically biotechnologies face a particularly long timeline to commercialization, with ATP funding often coming at an early point in the R\&D cycle. A recent survey of the seven projects in the tissue engineering study confirmed that the study was overoptimistic. None of the projects had achieved the level of benefits expected by that time. Three technologies now deemed the most successful continue to make technical progress and have entered at least the early stages of commercialization, but benefits are evolving much more slowly than projected for all of them. Three technologies failed to develop; one is in transition to a new company, with its future as yet uncertain.

The component-based software study was performed about five years later. The eight projects analyzed in depth received ATP funding in approximately the same time frame as the tissue engineering projects. Project selection for in-depth study emphasized projects with revenues to date and near-term prospects. All those selected had reached the commercialization stage when the study was performed. Estimated benefits from the eight projects reflected a mix of retrospective and prospective analysis, but with uncertainties greatly reduced for both compared with analyses of early-stage R\&D projects.

Theoretically, prospective benefit-cost analysis can model risk through probability distributions and various estimation tools. But pure 
uncertainty, with outcome distributions largely unknown and in instances in which little empirical data for comparable experience is available, is a different matter. From hindsight, ATP and possibly others have more empirical experience at this point to impose on analyses such as the tissue engineering study; however, the uncertainties are likely so great for studies performed very early in the technology life cycle that results of highly prospective benefit-cost analysis will probably not be very useful for program evaluation purposes. At best, predicted values should most likely cover a very broad range. An accurate probability distribution is likely to generate a low expected value if generated at an early stage.

Modeling and data estimation of prospective project impacts, including uncertainty, can be useful exercises in themselves; however, once such impacts have been estimated, there is temptation to use them for program evaluation purposes without adequate consideration of the original purpose of the exercise or the credibility and/or likely accuracy of the estimates.

As a practical matter, evaluation often cannot wait for fully retrospective results to be captured. Stakeholders need timely results of project and program progress. For $\mathrm{R} \& \mathrm{D}$ projects with a long time horizon, the trail to economic benefits often grows increasingly complex over time-researchers move on, companies disappear, and ATP-funded technology may resurface elsewhere. Program evaluators need to plunge in at some interim point.

\section{Summary}

In summary, highly prospective studies performed before technical risks and uncertainties have been overcome and business risks mitigated may not generate performance metrics that provide a credible or useful estimate of program impacts, even if they meet high standards of economic modeling and rigor. Results are likely not comparable to those obtained from retrospective analysis or even prospective analysis performed after technical success has been demonstrated but adoption is still in doubt. However, some combination of prospective and retrospective analysis may be reasonable if uncertainties have been mitigated through time, accomplishment, and substantive interviews with participating companies, their customers, and market experts. 


\section{v.}

\section{Identifying the Counterfactual and Attribution of Benefits}

\section{What Are the Issues?}

The issues are: What is the project being analyzed? And what is the counterfactual to the project that enables definition of project impact? Both questions entail considerable definitional and measurement challenges.

For a benefit-cost study, the project analyzed spans the life cycle from $\mathrm{R} \& \mathrm{D}$ through long-term outcomes and economic impact. Investment costs and benefits included in the analysis should reflect the increment over, and separable from, the counterfactual, or hypothetical situation that would have existed without the project being analyzed. Typically, the counterfactual situation is assumed to be the continuation of profits and products from a defender technology. The counterfactual describes the "losses" in the process of shifting to a newer technology from the older defender technology. The analysis seeks to capture the benefits of the newer technology less the losses from displacing the older one. In a dynamic environment, the counterfactual may be evolving in parallel with the technology being analyzed, and the defender technologies may be new technologies competing with it.

In practice, data to support analysis of actual outcomes relative to a counterfactual, as a controlled experiment, probably do not exist. Analysts use different approaches, or a mix of approaches, to define the project of study, from investment costs to long-term outcomes and economic impacts, and compare the project with a hypothetical alternative situation that reflects the researcher's best judgment as to what would have occurred in the absence of the project of analysis.

In S\&T federal program evaluation, "the project" is the R\&D that "the program" funded. In practice, the economic outcomes, or "benefits," often 
are the result of many investments of varying criticality. For example, public and private benefits from the sale and use of a product embodying specific new technology can derive from multiple public and private investments. And benefits may evolve from a stream of product generations that use increasing or decreasing amounts of the new technology resulting from the project.

The project could potentially be defined differently depending on whether one seeks to emphasize the return on investment from the point of view of a single government funding agency or the return on all investments that lead to a particular stream of benefits. Obviously, when both social returns (returns to all beneficiaries, including innovators, on all investments) and public returns (in ATP studies, public return is computed as returns, excluding those to innovators who received ATP funds, on ATP's investment) are presented together, the project analyzed for public return and social return purposes must be the same project, and benefits need to be traceable to the project. A mix is often needed: ATP-funded technology is traced forward into the marketplace and products in the product pipeline or in the marketplace are traced backward through the technology development process to see whether ATP played a role. In instances in which the stream of benefits clearly depended on ATP among other external investment sources, some method of benefit allocation may be needed. A social return analysis will need to include industry's full costs for $\mathrm{R} \& \mathrm{D}$, including early-stage $\mathrm{R} \& \mathrm{D}$ and product development costs.

\section{Contrasting Examples}

In practice, researchers first try to identify product outcomes with a direct connection to ATP-funded technology. They then conduct interviews to attempt to construct a counterfactual situation and elicit the ATP effect. Some companies have been working in the ATP area before applying to ATP. Some of them indicate that they would pursue similar goals without ATP but at a slower pace and with a poorer chance of success. Others indicate they could have done little or nothing without ATP and/or other government funding. The latter may be true for large companies pursuing new directions with ATP funding or for small start-up companies.

Cash flow-based benefit-cost studies have used a variety of mechanisms to model economic effects of an ATP project relative to a hypothetical situation in which ATP funding was absent. In general, this occurs in two stages: The researcher identifies the economic benefits from products and processes related to the ATP project and then, through a counterfactual analysis, establishes the portion of these benefits that are attributable to ATP. Table 4 summarizes many of the approaches used to define the benefits attributable to ATP. 


\section{Table 4. Identifying the Counterfactual and Attribution of Benefits- Contrasting Studies}

\begin{tabular}{|c|c|}
\hline Study & Approach \\
\hline Tissue engineering & $\begin{array}{l}\text { ATP project benefits are defined in regard to acceleration of } \\
\text { benefits and increased probability of technical success relative to a } \\
\text { hypothetical project without ATP. Public plus private benefits are } \\
\text { compared with public plus private investments to compute social } \\
\text { return on social investment. }\end{array}$ \\
\hline Component-based software & $\begin{array}{l}\text { Identified "project" that resulted in identifiable product sales and } \\
\text { compared public/private benefits with all costs associated with that } \\
\text { project to compute social returns }\end{array}$ \\
\hline $\begin{array}{l}\text { A-Si Detectors for digital } \\
\text { mammography and composites }\end{array}$ & $\begin{array}{l}\text { Company interviews indicated "no project without ATP"; public } \\
\text { benefits from product sales are compared with ATP investment to } \\
\text { compute public return on ATP investment. }\end{array}$ \\
\hline Photonics technologies & $\begin{array}{l}50 \% \text { attribution to ATP where two different federal programs } \\
\text { providing similar levels of funding were deemed jointly responsible } \\
\text { for realization of any benefits. Public return on ATP investment is } \\
\text { emphasized; social rates of return are also estimated. }\end{array}$ \\
\hline
\end{tabular}

The tissue engineering study defined project benefits in regard to acceleration of benefits and increased probability of technical success relative to a hypothetical project without ATP. The return on the ATP investment was the resulting incremental effect of acceleration of R\&D and greater technical success. Benefits of the general technical capabilities (in regard to improved patient outcomes anticipated when the technology was put to use) were estimated independently of these effects. However, the amount of benefit attributed to ATP was the portion of benefits estimated to be accelerated with ATP funding, the portion attributable to the bigger research project enabled by ATP funding and collaboration opportunities, or both.

The component-based software study took a very different approach. By focusing on ATP projects that were already in commercialization, researchers could identify market product outcomes that were related to ATP funding. The study estimated all public and private benefits of these products and compared them with all costs to bring the products to market, from R\&D through product development. The resulting metrics showing public plus private return on combined sources of investment did not attempt to quantify ATP's direct contribution. Most of the projects analyzed, however, were undertaken by tiny companies with little access to 
private or other public financing. The products assessed were their first and only products. ATP funding was obviously critical. The study discussed the need for ATP funding to achieve these benefits and the effects of ATP on acceleration as qualitative effects.

The amorphous-silicon detectors for digital mammography study and the composites cluster case studies all concluded from in-depth company interviews that the research project funded by ATP would not have been undertaken without ATP. These studies identified specific products or product or cost improvements and related user benefits resulting from the ATP project directly. Benefits to industry customers and end users of these products or improvements were attributed fully to ATP based on a counterfactual analysis in computing the return on ATP's investment. For example, for the amorphous-silicon detector project, the counterfactual was the existing, higher-cost digital mammography system. Benefits attributable to the ATP project were limited to those deriving from the ATP-funded manufacturing process that reduced costs of production and delivery of digital mammography systems and thereby enabled more patients to benefit from digital mammography than occurred with the earlier system.

In the study of a cluster of photonics projects, it was determined that ATP and NSF provided similar levels of funding to one of the projects. Company officials indicated a strong belief that neither funding would have occurred without the other and that the two agencies were jointly responsible for realizing any economic benefits from the company's first products. The study attributed to ATP $50 \%$ of estimated benefits from these impending products in computing the return on ATP's investment.

Note that computing social returns on investment (public plus private) on combined sources of investment does not require as strong an assumption about "causation" as does public return on ATP's investment. The social return set of metrics compares all benefits from a specific product/group with all investments required to generate those benefits. The estimation challenge is less one of ATP attribution than one of identifying product(s)/economic outcomes to target in the analysis and obtaining all relevant data for those products compared with the counterfactual products.

Obviously, when both social returns and public returns are presented together, "the project" analyzed for public return and social return purposes must be the same project, and benefits need to be traceable to "the project." If benefits to the project are traceable back to ATP among other projects or sources of investment, for purposes of computing the returns on the ATP investment, benefits may need to be allocated to 
different funding sources based on acceleration or other effects due to ATP funding or a pro rata share of investment costs provided by ATP.

\section{Summary of Counterfactual and Attribution of Benefits Issues}

Studies use a variety of mechanisms to model incremental benefits of an ATP-funded technology relative to a counterfactual situation in which ATP funding did not exist. Acceleration of benefits, increased likelihood of achieving benefits, and allocation in accordance with the amount or importance of individual funding sources (given multiple sources) have all been used.

The attribution question increases in complexity over the technology life cycle. Studies performed later in the commercialization phase encounter a complex weave of threads from and to ATP. The complexity may increase with the size of the company ATP funded (or its successor) if technology products are numerous, or past $\mathrm{R} \& \mathrm{D}$ investments were numerous, or both. The ATP lineage is clearer for most studies performed earlier; however, those studies face much more uncertainty about ultimate product benefits and unit sales.

Isolating the benefits of the ATP project can be equally or more difficult in retrospective analysis of fully commercialized technologies than analysis of R\&D outcomes at an earlier stage. Ultimately, ATP-funded technology may be embodied in multiple products of a company, each of which resulted from a number of different public and/or private funding sources and different R\&D projects. A mix of "tracing ATP-funded technology forward" into the marketplace and tracing products in the product pipeline or in the marketplace backward through the technology development process to see whether ATP played a role is often needed to (1) define the ATP project over its life cycle and (2) establish its impact relative to a hypothetical situation in which ATP funding was not available. 



\section{Which Metrics: Social Return on Investment and/or Public Return on Public (ATP) Investment?}

\section{What Are the Issues?}

Some studies and researchers emphasize return on ATP investment metrics; others emphasize social return on investment metrics. The social return metrics include both public and private benefits of a given project compared with all investment costs incurred in the R\&D and product development phases. The public return on ATP investment metrics focus on the public benefits attributable to ATP relative to ATP's investment. (Return on ATP investment metrics can be defined to include both public and private benefits; however, most of the studies that compute these measures have focused on public returns, in keeping with ATP's mission.) The social return metrics and public return on ATP investment metrics measure different things, and there is no consistent relationship between them.

\section{Return on Investment Measures}

- Public return on ATP investment: Return to nation attributable to ATP (defined in most ATP studies to exclude benefits to ATP project participants) on ATP investment

- Social return: Return to ATP project participants and nation on total investment from all sources

- Private return: Return to ATP project participants on total investments from all sources 


\section{Contrasting Examples}

Tables 5 and 6 illustrate the variation across just the more recent studies. The metrics for each of the eight component-based software case studies are presented in Table 5. The metrics for the comparison studies are shown in Table 6 . The component-based software study and digital video study computed social return metrics. The amorphous silicon detector for digital mammography study and the composites and photonics cluster study cases, performed by a different contract researcher, computed public return on ATP investment metrics. In addition to public return on ATP investment metrics, the photonics case studies estimated social rates of return, but not the other social return metrics.

Both sets of metrics have utility and merit. Social return metrics are rooted in the literature on the economics of innovation. Public return on program investment metrics have stronger roots in public finance and program evaluation. Tassey (2003, p. 19) suggests that "when the objective is to estimate the impact of the government role, two calculations should be made; one for the total impact (i.e., social return) and one for the contribution of the government subsidy (i.e., return on government investment)."

Work stemming from Edwin Mansfield in the late 1970s consistently finds evidence that social rates of return on R\&D investments exceed private rates of return and private hurdle rates. The "spillover gap," or difference

Table 5. Which Metrics? Contrasting Projects in Component-Based Software

\begin{tabular}{|c|c|c|c|c|c|c|}
\hline \multirow{2}{*}{$\begin{array}{l}\text { Component-based } \\
\text { Software }\end{array}$} & \multicolumn{3}{|c|}{ Social Return Metrics } & \multicolumn{3}{|c|}{ Public Return Metrics } \\
\hline & NPV (\$M) & $\mathrm{B}: \mathrm{C}$ & IRR (\%) & NPV (\$M) & $\mathrm{B}: \mathrm{C}$ & IRR (\%) \\
\hline Aesthetic Solutions & -1.2 & .37 & NC & \multirow{8}{*}{\multicolumn{3}{|c|}{ Not computed for this study }} \\
\hline Commerce One JV & 789 & 39 & 363 & & & \\
\hline Extempo & -1.22 & .63 & NC & & & \\
\hline Intermetrics & 29.6 & 9.6 & 103 & & & \\
\hline Real-Time Innovations & 2.06 & 1.8 & 31 & & & \\
\hline Sci Comp & 21 & 7.6 & 51 & & & \\
\hline Tom Sawyer & 52 & 18 & 136 & & & \\
\hline Xerox PARC & 1.2 & 1.2 & 13 & & & \\
\hline
\end{tabular}

Note: IRR = internal rate of return; $N C=$ not computed; NPV = net present value. 
Table 6. Which Metrics? Other Contrasting Studies

\begin{tabular}{|c|c|c|c|c|c|c|}
\hline \multirow{2}{*}{$\begin{array}{l}\text { Other Contrasting } \\
\text { Studies }\end{array}$} & \multicolumn{3}{|c|}{ Social Return Metrics } & \multicolumn{3}{|c|}{ Public Return Metrics } \\
\hline & NPV (\$M) & $\mathrm{B}: \mathrm{C}$ & IRR (\%) & NPV (\$M) & $\mathrm{B}: \mathrm{C}$ & IRR (\%) \\
\hline $\begin{array}{l}\text { Digital video } \\
\text { (midpoint) }\end{array}$ & 165.9 & 4.24 & 28.6 & \multicolumn{3}{|c|}{ Not computed for this study } \\
\hline $\begin{array}{l}\text { A-Si Detector } \\
\text { (base case) }\end{array}$ & NC & NC & NC & 219 & 125 & 69 \\
\hline \multicolumn{7}{|l|}{$\begin{array}{l}\text { Composites } \\
\text { (base cases) }\end{array}$} \\
\hline Applied Sciences & NC & NC & NC & 552 & 221 & 57 \\
\hline Lincoln Comp. & NC & NC & NC & 510 & 187 & 58 \\
\hline \multicolumn{7}{|l|}{$\begin{array}{l}\text { Photonics } \\
\text { (base cases) }\end{array}$} \\
\hline X-Ray Optics & NC & NC & 43 & 184 & 75 & 49 \\
\hline Ion Optics & NC & NC & 51 & 143 & 174 & 75 \\
\hline
\end{tabular}

Note: IRR = internal rate of return; NC = not computed; NPV = net present value.

between the social and private rates of return, is indicative of a market failure in funding R\&D. This body of work underlies the case for government support of R\&D and national innovation policy. R\&D projects that are cost shared between public and private sources, such as ATP projects, further imply that a relevant benefit-cost comparison involves both public and private benefits and investments.

The component-based software and digital video studies illustrate the difference between what is being measured in the social return metrics and what is measured in public return metrics and the variation in the effect of those differences. Although neither study presents separate public and private return metrics, the component-based software study provides measures of producer surplus (benefits captured by innovator firms) and consumer surplus (benefits captured by customers), which can be considered proxies for private benefits and public benefits, respectively. For the component-based software study, across all eight project cases, the consumer surplus was more than twice the producer surplus; however, there was a huge variation among projects. Surprisingly, the estimated producer surplus exceeded the consumer surplus for many of the smallcompany projects; however, the consumer surplus vastly exceeded the producer surplus for the successful Commerce One Joint Venture and for the Xerox PARC project. In the digital video study, the private benefits to U.S. companies were estimated to be very, very small compared with the 
public benefits. A public return on ATP investment analysis alone would fail to capture this variation among the separate private benefit and public benefit components of social benefits. And a public return on ATP investment analysis would further require a more in-depth assessment of the degree to which the consumer surplus, or public benefits, are attributable to ATP than was provided in the social return analysis. (See the prior section, "Identifying the Counterfactual and Attribution of Benefits," for further discussion of this issue.)

Of course, the cost side, as well as the benefits side of the analysis, is different for the social return metrics compared with the public return on ATP investment metrics. Full social costs span the earlier stages of R\&D, such as ATP funds, product development, and potentially production scaleup. Of course, this life cycle of costs affects computed rates of return. In addition, it greatly complicates the computation. The analysis requires considering a vast amount of historical data. The historical stream of investment cost data is difficult to come by. Private profit data, on a product basis, for estimating the private portion of benefits may not exist or may be highly confidential.

Researchers work hard to build a positive relationship with company representatives, including CEOs and presidents of small companies. In response, companies have been cooperative with these ATP studies, even though they generally require a full day of on-site interviews plus a number of phone calls and/or preparation of responses to written questions. However, the atmosphere changes when researchers probe explicitly for profit and cost of sales data. Across the board, researchers have settled for less in this area in return for forthcoming responses in other areas.

The social return metrics that include investments from multiple sources of funding of R\&D may tend to foster a broader definition of the R\&D project being studied than is most useful for program evaluation. One source of funding can overlap another one, and one product generation or $R \& D$ project outcome may overlap another. As a result, a narrow $R \& D$ project nucleated with specific federal funding can become buried among a chain of related R\&D projects, with outcomes partially in common. If the project is interpreted broadly, the federal program's effect on outcomesthat is, its additionality effect-becomes invisible in the resulting metric. Unless the project evaluated is traceable directly and more or less entirely to a single program that enabled the project, the social return metrics provide a general picture of the return on investment from multiple sources but may say little if anything about programmatic impact from a program evaluation perspective. 
This potential muddiness concerning project definition with the social return metrics does not appear to have been a major problem with ATP's component-based software and digital video studies. The two large joint ventures included in these studies-the Sarnoff-led joint venture covered by the digital video study and the Commerce One Joint Venture in the component-based software study-were uniquely ATP. It is unlikely that the resulting products would have come to be in a similar time frame without ATP. Five of the seven remaining projects covered in the component-based software study were start-up or otherwise very small companies that had received little funding besides ATP and whose only products were closely derived from their ATP project. Although several of these analyses included investment costs considerably beyond ATP's funding and company cost share on the ATP project, most of the additional funding directly supported commercialization of the ATP-funded technology. Therefore, the resulting social return metrics can be interpreted as "ATP project impact." The social return metric for the photonics project in which ATP and NSF provided similar levels of funding in a similar period of time would need to be interpreted more broadly.

\section{Summary of Return on Investment Measures}

The best strategy would appear to be to compute both social return metrics and metrics that show the impact of the specific federal program.

Metrics that focus specifically on the incremental effect of the specific federal program (for ATP, the public return on ATP's investment) have obvious utility for program evaluation. They also involve substantially less data. The challenge is to clearly define the funded project's outcomes compared with a hypothetical counterfactual in a way that pinpoints differences in outcomes attributable to the federal program being evaluated. (See the prior section, "Identifying the Counterfactual and Attribution of Benefits.”)

Social return metrics capture the return to all investors, which is particularly important for projects that are cost shared with industry. Industry proposes projects for federal cost share from which it anticipates a future return on its investment in the form of profits from resulting products and processes. Industry's return is of concern to the federal program because it provides the incentive to propose. Differences in the private component and public component of the social return further assist in assessing the potential market failure that justifies federal funding. 
Given the confidentiality of some of the data needed for computing social return metrics, public industry data may need to supplement company data. Relatively simple estimation techniques for social rates of return that draw on public data may be more practical than comprehensive analysis of actual private investment and profit data. Such simplified techniques may actually lead to more consistent methodologies and more comparable social return metrics across projects. However, little work has been done to develop practical social return methodologies, apply them illustratively, and test them for reasonable accuracy. 


\section{Adjusting for Timing Differences across Studies and Projects: Constant Dollars and Base Year for Discounting}

\section{What Are the Issues?}

Individual studies follow established good practice in adjusting for the varying value of the dollar in regard to both purchasing power and opportunity cost during the span of years covered by the study; however, projects studied start and end at different times. Studies are performed at different times and span different time periods. They do not reflect differences in purchasing power and opportunity costs across the series of studies.

\section{Constant Dollars}

Studies following the practice prescribed by OMB Circular A94 of estimating all cash flows in constant dollars use constant dollars of different years. For ease in estimating, benefits and costs are often estimated at their value in the year the study is conducted; for example, if the study is done in 1995, it is likely that all cash flows will be estimated in dollars of 1995 value. Some researchers follow other appropriate practices; for example, some express results in constant dollars of more than one year, such as the year the study is conducted and the year the project started.

Net present value study results expressed in 2005 dollars do not have the same purchasing power and thus are not equivalent or additive to net present value study results expressed in 2004 dollars or any other year's dollar purchasing power. They can, however, be adjusted to purchasing power equivalents with a straightforward procedure.

\section{Discount Rate}

When using constant dollars, the fundamental principle of cash flow-based benefit-cost analysis is that all costs and benefits be adjusted for the opportunity cost of capital over time before being aggregated across time: a dollar invested or earned sooner is worth more than a dollar invested or 
earned later in time because of the potential for earnings at some rate during the intervening period.

Cash flows that occur at different times during the history of a project are "discounted" to a common point in time to adjust for this difference in earnings opportunity. OMB Circular A-94 simplified the rate issue by stipulating that a rate of $7 \%$ (real earnings rate, above and beyond inflation) be assumed in adjusting benefits and costs of most federal programs and projects to a common point in time. ATP has used the $7 \%$ real rate for all of its cash flow-based benefit-cost studies listed in Table 1 except the tissue engineering study.

\section{Base Year for Discounting}

The most common practice, and that used by financial spreadsheet software such as Excel, is to discount cash flows incurred in a project back to "Time Zero," or one time period ahead of the first cash flow. For example, if the first cash flow-typically the first investment-occurred in 1996, and other cash flows are entered as annual amounts, Excel discounts all cash flows back to one year before that, or 1995, in computing the net present value. The discounting process typically assumes that cash flows occur at the end of the year. The beginning of the project is the beginning of the first year, which is equivalent to the end of the previous year (Zero). This practice of using Time Zero as the base year for discounting evolved from the use of discounted cash-flow analysis in evaluating the outcomes of alternative prospective investments under consideration that year. The study was being conducted at approximately Time Zero, dollar estimates were expressed in dollar values in Time Zero, and all future cash flows were discounted back to Time Zero. In this section, we interpret the start of the project as Time Zero.

Magnitudes of net present value metrics computed using the same discounting base year (and in the same constant dollars and with the same discount rate) can be compared with each other. Selecting the project with

the highest net present value would generate the maximum total net benefit from a single project. If multiple projects are feasible and independent of each other, their net present value metrics can be aggregated.

For program evaluation purposes, both prospective and retrospective analyses are done at different times in the program's history. Although, typically, studies of an individual R\&D project use one time period ahead of the start of the first cash flows (i.e., Time Zero) as the base year for discounting (as Excel does), the projects analyzed in different studies most likely started in different years. The interpretation of net present value 
results of different studies looked at collectively becomes somewhat problematic. However, various alternatives for adjusting net present value results to a common base year have interpretation problems as well. Should project metrics be adjusted to look at the projects from the perspective of a common point in time, for example, from the time of the comparative or aggregate study, or the start of ATP, or the start of the first project among a group? Or for project evaluation purposes, is it adequate to let the base year vary as long as all studies report metrics in the same constant dollar basis and the same discount rate? To build awareness, this report attempts to illuminate those questions. Answers will depend on specific program needs to compare or aggregate net present value results from different studies.

It is important to note that although the net present value metric will change with a change in base year and/or constant dollar year, the internal rate of return and benefit-to-cost ratio will not change. They remain constant regardless of the choice of base year or constant dollar year. Furthermore, they are better measures than the net present value for assessing the efficiency of a project in regard to output per dollar of input unless investment costs are the same for all projects. However, they cannot be used to assess the total dollar value of benefits generated by a single project or project aggregate. The net present value metric provides that information, and the net present value metric requires adjustment for different base years and different constant dollar years when results are aggregated.

\section{Examples of Effects of Constant Dollar and Base Year Differences}

A comparison of reported net present values with net present values adjusted to a common constant dollar year and base year provides examples of the effects of these differences. Because one purpose of looking at the results of multiple studies would be to identify the relatively more and less successful projects among a group of basically successful ones, we also look to see whether the order of projects changes from highest to lowest net present value.

Tables 7 and 8 illustrate the effects of constant dollar and base-year differences across a number of ATP's more recent studies. Reported net present values are compared with net present values adjusted to constant 2005 dollars and then further adjusted to a common base year of 2005 . 
Table 7. Adjusting for Timing Differences across Studies and Projects: Constant \$ and Base Year (Example 1: Ranking Does Not Change)

\begin{tabular}{|c|c|c|c|c|c|c|c|}
\hline $\begin{array}{l}\text { Component- } \\
\text { Based } \\
\text { Software } \\
8 \text { Cases }\end{array}$ & $\begin{array}{l}\text { Reported } \\
\text { NPV (\$M) }\end{array}$ & Rank & $\begin{array}{c}\text { Constant } \\
\$ \text { Year }\end{array}$ & $\begin{array}{l}\text { Base Year } \\
\text { for } \\
\text { Discounting }\end{array}$ & $\begin{array}{l}\text { Adj. NPV- } \\
\text { Constant } \\
2005 \$(\$ M)\end{array}$ & $\begin{array}{c}\text { Adj. NPV- } \\
2005 \text { as } \\
\text { Base Year } \\
\text { (\$M) }\end{array}$ & Rank \\
\hline Aesthetic Solutions & -1.2 & 7 & 2000 & 1994 & -1.3 & -2.8 & 7 \\
\hline Commerce One JV & 789 & 1 & 2000 & 1996 & 880 & 1,619 & 1 \\
\hline Extempo & -1.22 & 8 & 2000 & 1994 & 1.36 & -2.86 & 8 \\
\hline Intermetrics & 29.6 & 3 & 2000 & 1997 & 33.0 & 56.7 & 3 \\
\hline Real-Time Innovations & 2.06 & 5 & 2000 & 1995 & 2.30 & 4.5 & 5 \\
\hline SciComp & 21 & 4 & 2000 & 1994 & 23 & 49.3 & 4 \\
\hline Tom Sawyer & 52 & 2 & 2000 & 1995 & 58 & 114 & 2 \\
\hline Xerox PARC & 1.2 & 6 & 2000 & 1994 & 1.3 & 2.8 & 6 \\
\hline
\end{tabular}

Table 8. Adjusting for Timing Differences across Studies and Projects: Constant \$ and Base Year (Example 2: Ranking Changes)

\begin{tabular}{|c|c|c|c|c|c|c|c|}
\hline $\begin{array}{c}\text { Other Cash- } \\
\text { Flow-Based } \\
\text { Cases }\end{array}$ & $\begin{array}{l}\text { Reported } \\
\text { NPV (\$M) }\end{array}$ & Rank & $\begin{array}{l}\text { Constant } \\
\text { \$ Year }\end{array}$ & $\begin{array}{c}\text { Base Year } \\
\text { for } \\
\text { Discounting }\end{array}$ & $\begin{array}{c}\text { Adj. NPV- } \\
\text { Constant } \\
2005 \$(\$ M)\end{array}$ & $\begin{array}{c}\text { Adj. NPV_- } \\
2005 \text { as } \\
\text { Base Year } \\
\text { (\$M) }\end{array}$ & Rank \\
\hline Digital Video & 165.9 & 5 & 2002 & 1994 & 177.7 & 374 & 5 \\
\hline A-Si Detector & 219 & 3 & 2002 & 1997 & 235 & 403 & 4 \\
\hline $\begin{array}{l}\text { Composites: } \\
\text { Applied Sciences } \\
\text { Lincoln Composites }\end{array}$ & $\begin{array}{l}552 \\
510\end{array}$ & $\begin{array}{l}1 \\
2\end{array}$ & $\begin{array}{l}2003 \\
2003\end{array}$ & $\begin{array}{l}1996 \\
1997\end{array}$ & $\begin{array}{l}579 \\
535\end{array}$ & $\begin{array}{c}1,065 \\
920\end{array}$ & $\begin{array}{l}1 \\
2\end{array}$ \\
\hline $\begin{array}{l}\text { Photonics: } \\
\text { X-Ray Optics } \\
\text { Ion Optics }\end{array}$ & $\begin{array}{l}184 \\
143\end{array}$ & $\begin{array}{l}4 \\
6\end{array}$ & $\begin{array}{l}2004 \\
2004\end{array}$ & $\begin{array}{l}1993 \\
1999\end{array}$ & $\begin{array}{l}188 \\
146\end{array}$ & $\begin{array}{l}424 \\
219\end{array}$ & $\begin{array}{l}3 \\
6\end{array}$ \\
\hline
\end{tabular}


Table 7 examines the eight case study net present values reported in the component-based software study. All of these studies used a constant dollar year of 2000, but base years for discounting varied from 1994 to 1997. These variations were not enough to cause the relative order of the net present values across projects to change with the adjustment to a constant base year and constant dollar year.

Table 8 examines six cases that used a narrow spectrum of constant dollar years because the studies were all done fairly recently; however, the spectrum of base years used in discounting was broader, ranging from 1993 to 1999. The constant dollar adjustment alone was not enough to change the order of net present values. However, the additional effect of the base year adjustment was enough to cause the order of net present values across the six cases to change along with the significant change in magnitudes. The X-Ray Optics project moved from fourth position to third position, and the A-Si Detector project moved from third to fourth. The effects were greatest for projects in which the difference between the common base year and original base year for discounting were greatest; however, the revised ranking will now hold whatever common base year is used.

Figure 1 shows the formula for adjusting a reported net present value to constant 2005 dollars. The constant dollar adjustments were based on historical implicit price deflators for GDP reported for Q2 2005 in the September 2005 issue of Survey of Current Business (BEA 2005) (Tables C.1 and 1.1.9). Figure 2 shows the future value formula for adjusting reported net present values to a common 2005 base year.

\section{Figure 1. Adjusting to Constant 2005 Dollars}

NPV in constant $2005 \$=$

$$
\left[1+\frac{\text { Q2 2005 IPDGDP - IPDGDPstudy }}{\text { IPDGDPstudy }}\right] \times \text { Reported NPV }
$$

Where: IPDGDP is Implicit Price Deflator for GDP for Q2 2005 and IPDGDPstudy is IPDGDP for constant \$ year used in study

Source: BEA 2005, Tables C.1 and 1.1.9 


\section{Figure 2. Adjusting Base Year to 2005}

$$
\text { Adjusted NPV for Base Year } 2005=\text { NPV in constant } 2005 \$ \times 1.07^{\text {n }}
$$

Where: $\mathrm{n}=2005$ minus base year used in study

Illustrating the adjustments shown in figures 1 and 2 for the Digital Video case results shown in Table 8:

- Q2 2005 IPDGDP (Implicit Price Deflator for second quarter of 2005 published in September 2005 Survey of Current Business [BEA 2005], Table C.1) $=111.584$

- IPDGDPstudy (Implicit Price Deflator for constant dollar year used in study published in September 2005 Survey of Current Business [BEA 2005], Table 1.1.9) $=104.187$

- Applying the formula in Figure 1 to the reported NPV:

The adjusted NPV in constant 2005 dollars =

$$
\left[1+\frac{(111.584-104.187)}{104.187}\right] \times \$ 165.9 \text { million }=\$ 177.7 \text { million }
$$

- Applying the formula in figure 2 to adjust this NPV in constant 2005 dollars to 2005 as the base year for discounting = $\$ 177.7$ million $\times 1.07^{(2005-1994=11)}=\$ 374$ million.

Separate analyses, not shown, verified both empirically and mathematically that once all case study net present values are adjusted to a common base year, the base year can be changed again without further changing the order of the values. Magnitudes change, of course, as adjustments for opportunity costs move the base year of analysis backward or forward over time; however, the relative ordering does not change once net present values for all projects have been adjusted to a common base year.

There is little debate about the need, in theory, for constant dollar adjustments in comparing or aggregating net present value results from studies based on different constant dollar years. However, this adjustment might be considered relatively small and insignificant compared with other sources of measurement error in these studies. 
The issue of the base year for discounting is more complex and controversial. The assumptions behind the discounting process are confusing to evaluators and sometimes even to others who use return on investment metrics tools. A decision on what practice to follow requires discussion and an understanding of the meaning of the discounting process for individual projects and for an aggregate of projects.

Fundamentally, the purpose of the discounting process is to force comparison of the project(s) under study to a hypothetical alternative investment opportunity with a guaranteed $7 \%$ real rate of return. For a single project, the net present value represents the magnitude of the difference in outcome (excess over or under), in constant dollars, for the project compared with a $7 \%$ federal bond taken out at the start of the project and cashed in at the end of the project study period. When multiple projects that started at different times are being analyzed together, the comparison with the alternative investment with a $7 \%$ return becomes complicated. The common base year adjustment is a mechanism for appearing to simplify the issue but it creates other interpretation issues.

The common base year and common constant dollar adjustments force a consistent base year and dollar reference for a group of projects examined collectively and compared with a 7\% alternative project. However, these adjustments imply assumptions about earnings and costs of capital for individual projects prior to or beyond their individual study periods. For example, consider two projects that started in 1996 and 1998 and whose study periods ran until 2006 and 2008, respectively. To analyze the two projects together in the same study, a common practice would be to use a 1996 base year and to discount all benefits and investments from both projects to the beginning of the earliest project. This implies that a $\$ 1,000$ investment at the start of the second project in 1998 actually cost less than $\$ 1,000$. It cost only $\$ 873$ because of an assumed earnings potential at $7 \%$ during the two-year period before the investment occurred. (Benefits likewise would be discounted back to 1996 rather than 1998 and would thus be valued at fewer dollars.)

An alternative approach would be to use 2008 as the common year for discounting. With this approach, the assumption would be that all benefits (earnings) from all projects are reinvested until 2008 at a $7 \%$ rate. Use of an interim base year, for example, 2005 or the year the study is undertaken, assumes reinvestment of benefits at $7 \%$ per year through that year. Tables 7 and 8 use this last approach of adjusting reported net present values to the year the study was undertaken, an interim point among project cash flows. Initially, each project's cash flows had been discounted to their present values as of the start of the project and reported on that basis. For this study, reported present values were first 
adjusted to constant 2005 dollars and then further adjusted to a common "base" year 2005 by applying future value factors for $7 \%$ and the number of years from the start of the project through 2005. Assuming cash flows are stated in 2005 constant dollars, this process is equivalent to the alternative approach of adjusting individual cash flows from each project to 2005 by discounting post- 2005 cash flows to 2005 and computing future values of pre-2005 cash flows and adding them all together with 2005 cash flows. The approach used in this study in Tables 7 and 8 is more straightforward and can be implemented directly from net present values computed by Excel and those typically reported.

The following are a few considerations in the decision as to whether to adjust for differences in discounting base years for purposes of comparing or aggregating results.

- Projects are funded from different annual budgets and budget decision environments, which argues for the "floating" base year across studies as long as the base year is consistently the start of the projects evaluated. The benefit-cost calculation is then aligned with the budgetary economic events. Aggregation of results of studies with different base years poses some interpretation questions; however, this approach requires no assumption about alternative investment opportunities before and after the time of actual cash flows from the projects analyzed.

- Using "the time of the study valuation" for handling both constant dollars (purchasing power) and discounted value (opportunity cost of capital) has the advantage of ease of interpretation, particularly for retrospective analysis that involves aggregation across studies for program evaluation purposes. The reader understands the value of a dollar at the current time, which often approximates the time of the study. Using the "time of the study" as the base year assumes that all cash-flow benefits spun out of a project or put into a project are invested at the discount rate from the time they occur until the time of the study.

- Alternatively, using the start of ATP (in 1990) as the base year, or the start of the first project in an aggregate group being studied, has been considered meaningful. ATP's photonics and composites cluster studies and the component-based software study used this latter approach for analyzing a group of projects. Cash flows of all projects studied are discounted back to the start of the earliest project. As a result, in the aggregate analysis, benefits from later projects are downsized compared with earlier benefits from earlier projects. For example, consider the photonics cluster study, in which the X-Ray Optics individual case study analysis used a 1993 base year for discounting (first cash flows in 1994), the Ion Optics individual case study used 1999 as the base year for 
discounting (first cash flows in 2000), and the aggregate cluster analysis used 1993 as the base year. The individual Ion Optics case study showed the project to have a net present value of $\$ 143$ million; however, within the aggregate cluster analysis, the Ion Optics project contributed only $\$ 95$ million as a result of discounting benefits and costs back to 1993 as the base year rather than to 1999.

- The adjustment to restate project outcomes relative to a common vantage point base year, such as "time of the study" or "start of ATP," or any other point in time, can be done from previously reported metrics. The process then can be repeated over time for different base years and different constant dollar years.

Again, results of using a different base year have different magnitudes and different interpretations. Using the project start as the base year means that all later positive and negative cash flows are adjusted (discounted) downward at $7 \%$ compounded annual rate to compute the net financial advantage relative to the alternative safe investment made at the project start and held until the end of the project. By using some later year as the base year, for example, the year the study is being undertaken, all cash flows are adjusted upward for the equivalent of $7 \%$ annual compounded earnings on those cash flows (or lost earnings in the case of negative cash flows) until that ultimate base year. When multiple projects are examined together and cash flows are adjusted to a common "project start" or other common base year of analysis, the $7 \%$ compounding or discounting effect is extended beyond the project periods of at least some projects in the aggregate.

Using the same constant dollar year and base year for discounting, as was done in Tables 7 and 8, has the intuitive appeal that resulting dollar amount metrics can be interpreted more easily. If they are the same as the year the study is performed, dollar results have even more intuitive meaning in that they can be compared with what that amount of money will buy at that time. This concept parallels the original concept of using the project start as the base year for evaluating prospective investment alternatives under consideration that year.

\section{Summary of Analysis of Net Present Value Adjustments}

Evaluators and other users of the net present value (or net benefits) metrics resulting from cash flow-based benefit-cost studies need to recognize the effects of different constant dollar years and different base years on proper interpretation and use of these results. For purposes of presenting results of a single project case study, the traditional approach that uses the beginning of the project funding year as the base year may be adequate as long as all 
use the same constant dollar year and thus net present values reflect purchasing power equivalents. However, when results of different studies are presented collectively, the interpretation is fuzzy.

In instances in which multiple projects are analyzed in a single study or in which results of multiple studies are considered together to compose a minimum estimate of portfolio performance, adjustment to constant dollars and a common base year for all projects will most likely be necessary.

Adjustment to a common base year and constant dollar year after the study of an individual project is completed is relatively straightforward and may be a better solution than trying to impose a standard "fixed" base year and constant dollar year for all studies. Many practitioners are committed to the traditional concepts of base year as the "start of the project." The traditional approach provides a consistent starting point for observing the traditional metrics before considering what adjustments might be needed for comparability or aggregation with other studies.

Adjustments, particularly of the base year used in computing net present value, will require programmatic consideration of what basis makes most sense to the evaluation objective. Adjusting all study results to 1990, for example, would evaluate net benefits whenever they occurred back to the start of the ATP as if the pool of funds for them existed then and could have been invested in the interim. It does not recognize that most of the projects studied were funded out of later budgets. The cluster and portfolio analyses ATP has performed use the year the first project started as the base year. All other cash flows were discounted back to that year. This process is equivalent to computing the net present value for each project separately using that project's start as the base year and then discounting the resulting set of net present values back to the start of the first project.

Adjusting all net present value results forward to the time a collective assessment is being performed, as is done in Tables 7 and 8 , reflects the assumption that the net present value reported as of the base year of each study is reinvested at the $7 \%$ discount rate until the time of the study. Equivalently, the assumption is that net cash flows generated in any year from any project are reinvested at $7 \%$ until the year the study is performed. That assumption may be a more useful than assuming that all funds for all projects were available at the beginning of ATP or the start of the first of several projects studied. 


\section{VIII. \\ Conclusions and Future Work}

ATP's efforts during the past two years to document and investigate the significance that methodological differences have across its benefit-cost studies have demonstrated both the utility and commonality of the studies, but also the complexities beyond pure estimation difficulties. The challenges do not appear insurmountable. As for other program evaluation tools, communication and training requirements are significant. However, the basic underpinnings of cash-flow benefit-cost techniques are well established in accounting, finance, and business, and they are adapted to capture societal benefits in public finance and economics literature.

Practitioners have created a body of work that is consistent with good practice as spelled out in the business, public finance, and economics literature. The challenges are in adapting "one-at-a-time case studies" or studies of small groups of projects to a more comprehensive portfolio analysis. The cost and time of doing high-quality studies precludes doing them for all projects funded by a program, never mind doing them in a similar time frame; however, program evaluators and users of study results will need to consider results of different studies at a given time to be able to aggregate and/or compare them. Analyses of key differences across ATP's considerable body of such studies to date have helped us to assess the significance of the differences and to pose solutions.

In general, the programs being evaluated, such as ATP, will not be undertaking such studies themselves but rather will be contracting them to consultants with experience in this type of work. It will be necessary for the program sponsors of this work to communicate the issues to their hired consultants. ATP's experience indicates that the number of consultants with substantial experience in benefit-cost analysis of publicly funded R\&D is relatively small; furthermore, even the experienced consultants in this area focus on the study at hand, not how that study will be aggregated with 
studies done by other researchers or with their own earlier studies. Different experts have somewhat different opinions about solutions to problem areas in which multiple approaches have merit, but inconsistency in approach impedes the interpretation and use of results.

The immediate goal is to circulate this report to users of benefit-cost results and to benefit-cost analysis practitioners in NIST as part of the formal review process and subsequently to ATP contractors and others. Feedback is sought and anticipated with the hope that a living, working document will support a more formal, uniform, standard-setting process for benefitcost analysis in the future. 


\section{References}

Advanced Technology Program (ATP). 1996. Meeting with Edwin Mansfield at University of Pennsylvania in June 1996. Jeanne Powell and Dr. Stephen Weber (Building and Fire Research Laboratory, National Institute of Standards and Technology) met with Dr. Mansfield to discuss specific research issues concerning application of Dr. Mansfield's recent report for ATP, Estimating social and private returns from innovations based on the Advanced Technology Program: Problems and opportunities.

American Society for Testing and Materials (ASTM) International (Subcommittee E06.81 Chair Harold E. Marshall, Building and Fire Research Laboratory, National Institute of Standards and Technology). 2004. ASTM Standards on Building Economics, 5th ed. West Conshohocken, PA: ASTM International.

Bernstein, Jeffrey I., and M. Ishaq Nadiri. 1988. Interindustry R\&D spillovers, rates of return, and production in high-tech industries. AEA Papers and Proceedings 78 (May): 433.

Bureau of Economic Analysis (BEA). 2005. Survey of Current Business 85 (September 2005): D4 (Table 1.1.9 Implicit price deflators to Gross Domestic Product), D48 (Table C.1 GDP and other major NIPA Aggregates). http://www.bea.gov/bea/pub/0905cont.htm.

GPRA. 1993. Government Performance and Results Act of 1993. Office of Management and Budget, Executive Office of the President. http://www.whitehouse.gov/omb/mgmt-gpra/gplaw2m.html

Jaffe, Adam B. 1996. Economic analysis of research spillovers: Implications for the Advanced Technology Program. NIST GCR 97-708. Gaithersburg, MD: National Institute of Standards and Technology. 
1998. The importance of "spillovers" in the policy mission of the Advanced Technology Program. Journal of Technology Transfer 23 (summer 1998): 11-19.

Mansfield, Edwin. 1995. Innovation, technology and the economy: The selected essays of Edwin Mansfield, Vol. I. Brookfield, United Kingdom: Edward Elgar.

- 1996. Estimating social and private returns from innovations based on the Advanced Technology Program: Problems and opportunities. NIST GCR 99-780. Gaithersburg, MD: National Institute of Standards and Technology.

Mansfield, Edwin, John Rapoport, Anthony Romeo, Samuel Wagner, and George Beardsley. 1977. Social and private rates of return from industrial innovations. Quarterly Journal of Economics 91 (May 1977): 221-40.

Nadiri, M. Ishaq. 1993. The contribution of research and development and economic growth. NBER working paper. Cambridge, Massachusetts: National Bureau of Economic Research.

Office of Management and Budget (OMB). 2004. Office of Management and Budget Examiner Training on Program Evaluation by the Federal Evaluators Group, October 6.

- 1992. Office of Management and Budget Circular A-94. Guidelines and discount rates for benefit-cost analysis of federal programs. http://www.whitehouse.gov/omb/circulars/a094/a094.pdf.

Scherer, F. M. 2005. Edwin Mansfield: An appreciation. Journal of Technology Transfer 30 (January 2005): 3-9.

Tassey, Gregory. 2003. Methods for assessing the economic impacts of government R\&D. Planning report 03-1, p. 19. Gaithersburg, MD: National Institute of Standards and Technology. http://www.nist.gov/public_affairs/budget.htm.

Teece, David J. 2005. Technology and technology transfer: Mansfieldian inspirations and subsequent developments. Journal of Technology Transfer 30 (January 2005): 17-33. 


\section{ABOUT THE ADVANCED TECHNOLOGY PROGRAM}

The Advanced Technology Program (ATP) is a partnership between government and private industry to conduct high-risk research to develop enabling technologies that promise significant commercial payoffs and widespread benefits for the economy. ATP provides a mechanism for industry to extend its technological reach and push the envelope beyond what it otherwise would attempt.

Promising future technologies are the domain of ATP:

- Enabling or platform technologies essential to development of future new products, processes, or services across diverse application areas

- Technologies where challenging technical issues stand in the way of success

- Technologies that involve complex "systems" problems requiring a collaborative effort by multiple organizations

- Technologies that will remain undeveloped, or proceed too slowly to be competitive in global markets, in the absence of ATP support

ATP funds technical research, but does not fund product development - that is the responsibility of the company participants. ATP is industry driven, and is grounded in real-world needs. Company participants conceive, propose, co-fund, and execute all of the projects cost-shared by ATP. Most projects also include participation by universities and other nonprofit organizations.

Each project has specific goals, funding allocations, and completion dates established at the outset. All projects are selected in rigorous competitions that use peer review to identify those that score highest on technical and economic criteria. Single-company projects can have duration up to three years; joint venture projects involving two or more companies can have duration up to five years.

Small firms on single-company projects cover at least all indirect costs associated with the project. Large firms on single-company projects cover at least 60 percent of total project costs. Participants in joint venture projects cover at least half of total project costs. Companies of all sizes participate in ATP-funded projects. To date, nearly two out of three ATP project awards have gone to individual small businesses or to joint ventures led by a small business.

Contact ATP for more information:

- On the Internet: www.atp.nist.gov

- By e-mail: atp@nist.gov

- By phone: 1-800-ATP-FUND (1-800-287-3863)

- By writing: Advanced Technology Program, National Institute of Standards and Technology, 100 Bureau Drive, Stop 4701, Gaithersburg, MD 20899-4701

\section{ABOUT THE AUTHOR}

Jeanne Powell is Senior Economist in the Economic Assessment Office, ATP, where she manages contractor evaluation studies, develops methodologies for applying benefit-cost analysis to ATPfunded industry R\&D projects, and advises on performance measurement issues. She developed ATP's Business Reporting System and has published a number of reports of ATP progress, including Different Timelines for Different Technologies (2002), Development, Commercialization, and Diffusion of Enabling Technologies: Progress Report (2000), Business Planning and Progress of Small Firms Engaged in Technology Development through the Advanced Technology Program (1999), and Development, Commercialization, and Diffusion of Enabling Technologies: Progress Report for Projects Funded 1993-1995 (1997). Her previous experience includes serving small businesses as a private Certified Public Accountant (CPA), performing corporate audits for regional CPA firms, performing several stints as a federal government economist, and Professor of Economics, Business Statistics, and Accounting with Montgomery College. 